\title{
Collapse limit state definition for seismic assessment of code-conforming RC buildings
}

\author{
M. Terrenzi ${ }^{1}$ D $\cdot$ E. Spacone ${ }^{1} \cdot$ G. Camata ${ }^{1}$
}

Received: 6 January 2018 / Accepted: 23 August 2018 / Published online: 1 September 2018

(c) The Author(s) 2018

\begin{abstract}
This paper presents a study on the selection of engineering demand parameters (EDPs) for the definition of collapse for code-conforming reinforced concrete buildings. The definition of collapse for buildings is not unique, as different codes and authors define it with respect to different EDPs and different values of the EDPs. Since collapse is associated with large plastic deformations, collapse is typically defined by deformation, displacement, and eventually energy EDPs. The EDPs can be either local when they refer to a single structural element response parameter (such as element rotation with respect to the chord) or global when they refer to an overall building response parameter (such as inter-story drift or top floor displacement). The Italian buildings code NTC2008 and Eurocode 8 use the chord rotation as EDP, while FEMA 356 and other North American literature use inter-story drift ratio. This study compares different definitions of EDPs and different values of the selected EDPs by analyzing two code-conforming benchmark buildings, one six-story and the other nine-story high, designed according to Italian code. Multiple-stripe, non-linear dynamic analyses are carried out on the two buildings modeled with concentrated hinges. The results show that different collapse definitions lead to very different safety evaluations and point to the need for the definition of a single EDP and a single value to make collapse analyses (and risk assessment) studies comparable.
\end{abstract}

Keywords Collapse $\cdot$ EDP $\cdot$ Reinforced concrete $\cdot$ Seismic

\section{Introduction}

This work was inspired by the study that the authors carried out within the Italian RINTC project (RINTC Workgroup 2018), a multi-year research initiative, whose aim is to assess the risk of collapse of code-conforming buildings designed according to the Italian Building Code NTC 2008. The RINTC project deals with reinforced concrete, precast reinforced concrete, masonry, steel, and base-isolated structures. The present work focuses on assessing collapse of cast-in-place reinforced concrete buildings. Only residential

\footnotetext{
M. Terrenzi

marco.terrenzi@unich.it

E. Spacone

espacone@unich.it

G. Camata

guido.camata@unich.it
}

1 Department of Engineering and Geology, University G. D’Annunzio of Chieti-Pescara, Viale Pindaro 42, 65127 Pescara, Italy buildings are considered. The definition of building collapse is not unique (Villaverde 2007). Different codes and different authors have not converged to similar approaches to define collapse. In a performance framework, collapse can be defined as the inability of the structures to guarantee a given performance for a given earthquake. At collapse, a structures loses its capability to carry lateral loads. Collapse can be assessed through either local or global engineering demand parameters (EPDs) at the local (element) or global level (Whittaker et al. 2004). Local EDPs typically re. Collapse depends on a number of factors, all affected by the cyclic response of the structure to a given earthquake. This work compares different collapse definitions available in building codes (EC8, NTC2008), design guidelines (FEMA356, SEAOC Vision 2000), and published literature (Camata et al. 2017; Ghobarah 2004). The comparison between the different definitions is carried out by analyzing two different code-conforming RC buildings (a six and a nine-story building) in three different configurations: Bare Frame (BF), Infill Frame (IF), and Pilotis Frame (PF). 


\section{Definition of collapse EDPs}

EDPs are structural response quantities that can be used to asses the performance of structural and nonstructural components and systems (Whittaker et al. 2004). They can be defined as

- local EPSs, such as chord rotation and Local Damage Index;

- global EDPs, such as inter-story drift ratio (IDR), roof drift ratio (RDR), Global Damage Index.

The collapse EDPs are hereafter divided into those defined in design codes and guidelines and those proposed in the published literature. Table 1 summarizes the EDPs discussed in the next two sections.

\section{Collapse EDPs by design code and guidelines}

There is no unique definition of the collapse EPDs in building codes. Eurocode 8 (and similarly the Italian NTC2008 building code) does not specifically define collapse EPDs for code-conforming buildings, but limits the EDP definitions to existing buildings. In any case, the EDPs in EC8 and NTC2008 are all local and refer to the response of the single structural members. The performance with respect to brittle mechanisms (typically shear mechanisms) is assessed by checking that the shear demand does not exceed the shear capacity in terms of applied vs resisting forces. For ductile mechanisms (bending in beams and axial-bending behavior in columns), performance is assessed by checking that the chord rotation does not exceed rotation limits defined for different limit states. In principle, collapse occurs when the first structural element in a structure reaches collapse in either a brittle or a ductile mechanism. SEAOC Vision 2000 and FEMA356 (which also deals with existing buildings), on the other hand, use a global EDP, more precisely the inter-story drift ratio (IDR), difference limit values are given in the two guidelines. Furthermore, there is no distinction between building models with and without infills.

\section{Other collapse EDPs}

Several papers have been published over the years dealing with this topic. Starting with the most recent studies, Camata et al. (2017) use the roof drift ratio (RDR) as global EPD in their study on the implicit risk of code-conforming Italian buildings (RINTC) (RINTC Workgroup 2018). The RDR capacity in each building direction is defined as the RDR corresponding to a $50 \%$ capacity drop in base shear after the peak shear force capacity in the pushover curves. RDR demand is assessed from non-linear time history analyses. The approach is schematically shown in (Fig. 1a).

An alternative global EDP is the inter-story drift ratio (IDR). Ghobarah (2004) defines different IDR limit values for different $\mathrm{RC}$ frames, mainly ductile moment resisting frames, and moment resisting frames with infills. In the first case, collapse is reached when IDR $>3.0 \%$, in the second case when IDR $>0.8 \%$. In this study, for the BF buildings, we will use the values proposed by Ghobarah (2004) for the ductile moment resisting frames, and for the IF buildings, the values proposed for the moment resisting frames with infills, and for the PF buildings, the two approaches are combined (ground floor assessed with $3.0 \%$ IDR limit and remaining floors with $0.8 \%$ ).

\section{Case study definition}

The buildings are all intended for residential use (except for the ground floor level indented for commercial use) and are characterized by regularity both in plan and in elevation. As shown in Fig. 2, the architectural plan includes four apartments per floor; though from a structural viewpoint, there are two structures separated by a seismic gap in the central axis of symmetry. Each floor (two apartments) has a 252 $\left(\mathrm{m}^{2}\right)$ area. A single structure is studied hereafter.

The ground level is $3.4(\mathrm{~m})$ high, and all other stories are $3.05(\mathrm{~m})$ high. Two buildings are studied here, one six-story and the other nine-story high, both with a flat roof and identical floor plans (except for the columns sizes).
Table 1 Collapse EDPs used in this work

\begin{tabular}{ll}
\hline Name & Collapse EDP \\
\hline NTC2008 and EC8 & Achievement of chord rotation in the first structural element (column) \\
FEMA 356 & IDR $\geq 4 \%$ (transient or Permanent) \\
Vision 2000 & IDR $\geq 2.5 \%$ (transient or permanent) \\
RINTC (Camata et al. 2017) & RDR. Collapse is reached when demand RDR reaches RDR capacity, \\
& assessed as RDR corresponding to 50\% drop in base shear capacity in \\
& Pushover analysis \\
Ghobarah (2004) & IDR: BF $\geq 3 \%$, IF $\geq 0.8 \%$, PF ground floor $\geq 3 \%$ and remaining floor $\geq$ \\
& $0.8 \%$
\end{tabular}


Fig. 1 RINTC collapse EDP (Camata et al. 2017)

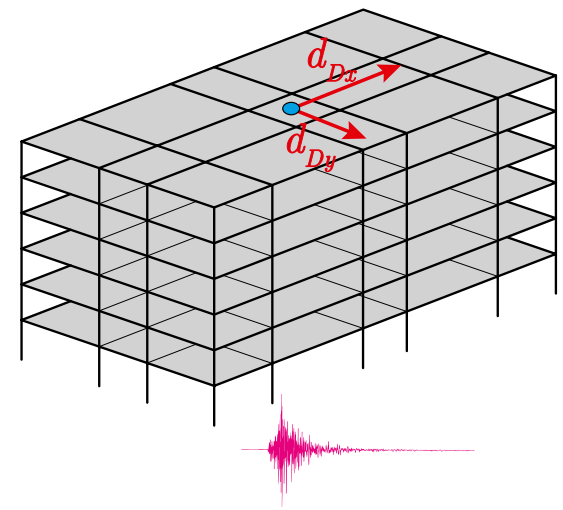

(a) Demand

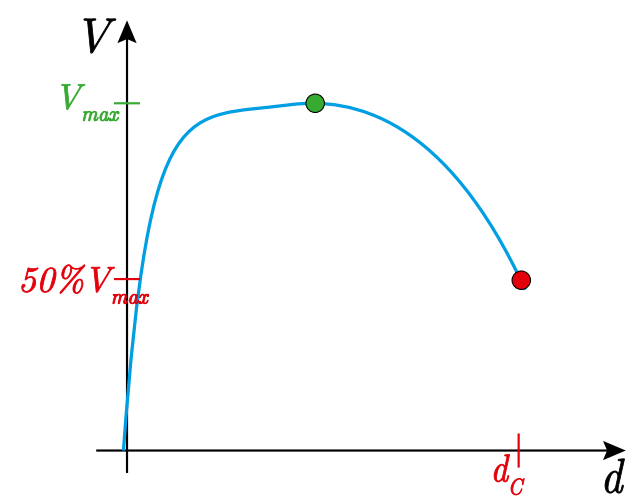

(b) Capacity

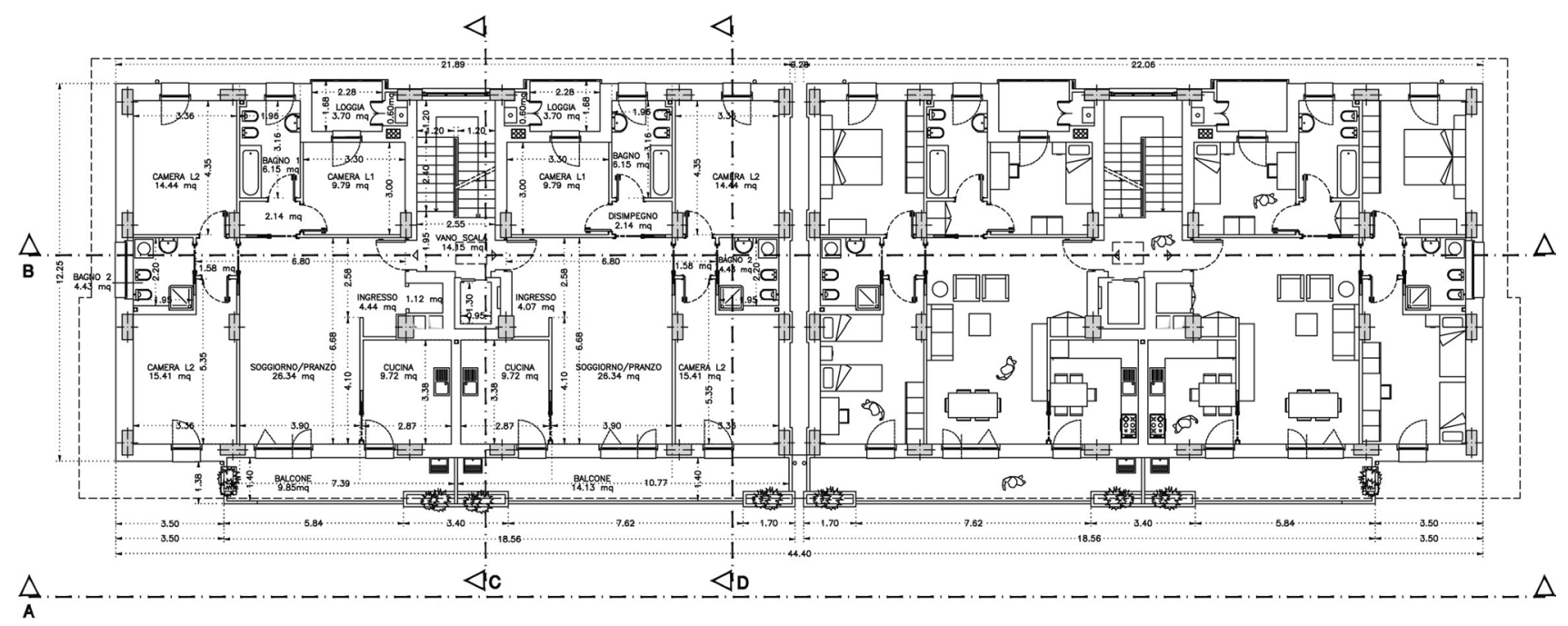

Fig. 2 Typical architectural plan with RC columns positions

\section{Building design}

Design of the RC buildings followed the Italian NTC 2008 design code. All buildings were designed in low ductility class using response spectrum analysis. Two different seismic sites were considered: Naples (six-story) and L'Aquila (nine-story), both on soil type C. The structures are moment resisting frames assumed fixed at the base. In the design linear elastic frame model, the beams and columns are considered cracked with resulting reduced stiffness of $50 \% I_{\text {trv }}$ and $75 \% I_{\text {col }}$, respectively. The stairs were designed and modeled with knee beams. The minimum column size is $35(\mathrm{~cm})$ the outer beams are all deep, while all internal beams are flat (for this reason, the building automatically falls into the low ductility category of NTC 2008). It is commonplace in Italy to use masonry infills for the building outer walls. Infills may be interrupted at the ground level to allow large openings (for garage and/ or commercial use). For the above reasons, three different infill configurations are considered in this study, as summarized in Fig. 3:

- Bare Frame (BF), the infills contribute only in terms of dead load. Their stiffness and load carrying capacity are neglected both in linear (building design) and non-linear analyses.

- Infill Frame (IF), the infills are regularly distributed in plan and in elevation in the buildings' outer walls. The infills only contribute to dead load in the linear analyses (design) and are explicitly included in the non-linear analyses.

- Pilotis Frame (PF), the infills are identical to the IF, but are totally absent at the ground level. The infills only contribute to dead load in the linear analyses (design) and are explicitly included in the non-linear analyses.

The design of the BF and IF configurations is identical, because during design, the infills are not modeled as 


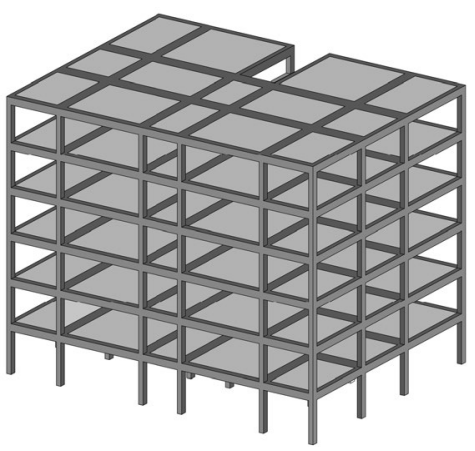

(a) $\mathrm{BF}$

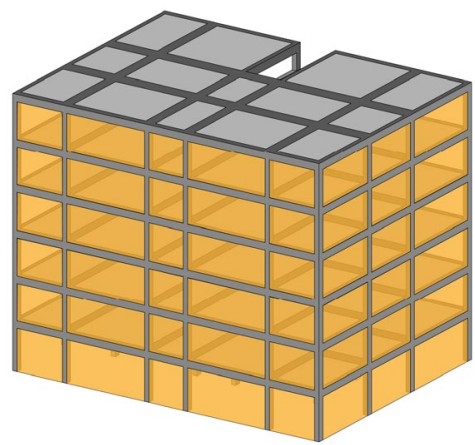

(b) IF

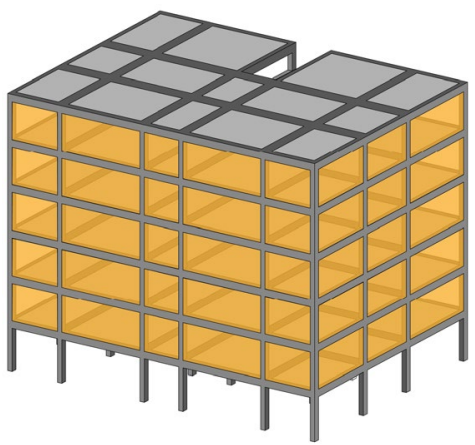

(c) $\mathrm{PF}$

Fig. 3 Infill configurations

Table 2 Summary of buildings design data

\begin{tabular}{lllllc}
\hline & & $\Sigma A_{\text {pls }} / A_{\text {floor }}(\%)$ & $\rho_{\text {tr.de }, 1 L}(\%)$ & $\rho_{\text {tr.de, } 1 L}(\%)$ & $\rho_{\text {pls,gr }}(\%)$ \\
\hline Napoli-6p & BF-IF & 2.17 & 0.72 & 0.84 & 1.46 \\
& PF & 2.17 & 0.72 & 0.84 & 1.48 \\
L'Aquila-9p & BF-IF & 3.01 & $0.75 \div 1.80$ & $0.9 \div 1.26$ & $1.45 \div 2.08$ \\
& PF & 3.01 & $0.75 \div 1.80$ & $0.9 \div 1.26$ & $1.45 \div 3.19$ \\
\hline
\end{tabular}

$\Sigma A_{\text {pls }} / A_{\text {floor }}$ total column area at the ground floor/total floor area

$\rho_{\text {tr.de, } 1 L}$ first level average deep beams longitudinal steel ratio

$\rho_{\text {tr.fl, } 1 L}$ first level average flat beams longitudinal steel ratio

$\rho_{\text {pls,gr }}$ ground floor average base floor columns steel ratio
Table 3 Summary of buildings modal parameters

\begin{tabular}{lllll}
\hline & $T_{x}(\mathrm{~s})$ & $M_{x}(\%)$ & $T_{y}$ & $M_{y}(\%)$ \\
\hline Napoli-6p & 0.88 & 82 & 0.80 & 83 \\
Aquila-9p & 1.47 & 79 & 1.24 & 77 \\
\hline
\end{tabular}

structural elements, but are only included as dead loads. For the PF configurations, the Italian building code NTC20087.2.3 considers that in buildings with an infill distribution irregular in elevation (such as the case of PF buildings), damage may concentrate in a single story. For this reason, the code prescribes that all actions be increased by $40 \%$ for the vertical elements in stories with an infill reduction. The following materials are used: concrete $\mathrm{C} 28 / 35$ and steel B450C. Table 2 reports buildings main design data, while Table 3 summarizes the buildings modal parameters (periods and modal participation mass for the first two modes).

\section{Non-linear modeling}

Opensees McKenna (2011) was used to run the non-linear analyses. Because the buildings were designed following capacity design principles, only non-linear ductile mechanisms are of interest here. Beams and columns are modeled with end concentrated hinges connected by linear elements. The hinge model is the well-tested model by Ibarra et al. (2005), in its most recent OpenSees implementation "ModIMKpeakOriented" (Lignos and Krawinkler 2012).

The model is defined through seven parameters, five for the monotonic envelope and two for the degradation mechanism (the beams have non-symmetric backbones, and thus, double parameters are needed).

These parameters are (refer to Fig. 4): yield moment $\left(M_{y}\right)$, elastic stiffness $\left(K_{e}\right)$, strain hardening ratio $\left(M_{u} / M_{y}\right)$, pre-capping rotation $\left(\theta_{\text {cap }}\right)$, post-capping rotation $\left(\theta_{\mathrm{pc}}\right)$, and two cyclic deterioration parameters $(\lambda, c=1)$.

The sections yield that moments are determined using the section analysis approach proposed by Panagiotakos and Fardis (2001). The remaining parameters are computed using the predictive equations by Haselton et al. (2009). This model can be used to describe the moment-rotation relationship in a single plane of flexure, for a fixed axial load. The columns' parameters were calibrated by defining two distinct and independent relationships in the two orthogonal bending planes, evaluated for the axial force produced by the gravity loads of the seismic load combination. The beams' parameters define non-symmetrical relationships, given the sections' different upper and lower reinforcements. 
Fig. 4 Hinge model shape and main parameters: element assembly (zero-length inelastic end hinges + elasticBeamColumn element) (left), momentrotation law (backbone) according to Ibarra et al. (2005) model (right)
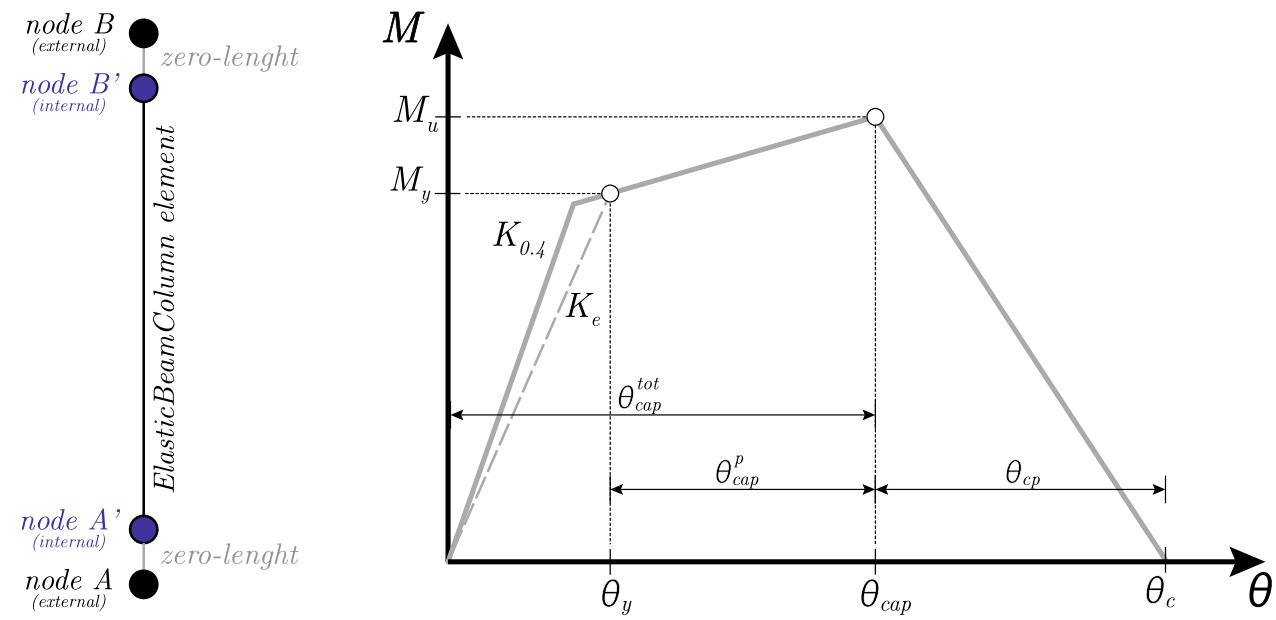

The beam and column elements are the assembly of an elastic element and of the two zero-length hinges, as shown in Fig. 4.

Since the three elements are in series, the thresholds of the member bending moment capacity are that of the inelastic hinges, while the deformation thresholds are a function of the stiffness ratio $n=k_{s} / k_{e}$, where s and e subscripts denote the section and the elastic element, respectively [Ibarra et al. (2005)_Appendix B]. In this paper, $n=10$.

Modeling of the stairwell elements requires particular attention, because the large axial force variations in the inclined beams induce large shear forces in the adjoining members. In the non-linear model, the axial stiffness of the elasticBeamColumn staircase elements was set to zero, and an inelastic bar element was added in parallel, with a nonsymmetric elasto-plastic constitutive law for compression and tension (uniaxial material hysteretic).

The contribution of the masonry infill panels was represented by a diagonal strut element (compression only), using the models proposed by Decanini and Fantin (1987), Bertoldi et al. (1993), and Decanini et al. (2004) that describe the monotonic and cyclic behavior of the infill as a function of the mechanical and geometrical characteristics of the masonry infill.

In this project, it was assumed that the infills are made of $30(\mathrm{~cm})$ thick hollow bricks with the following mechanical characteristics:

$$
\begin{aligned}
& \sigma_{0}: \text { vertical stress }[0(\mathrm{MPa})] \\
& \sigma_{\text {mo }}: \text { compression strength }[6(\mathrm{MPa})] \\
& \tau_{\text {mo }}: \text { shear strength }[0.77(\mathrm{MPa})] \\
& u \text { : sliding strength }[0.54(\mathrm{MPa})]
\end{aligned}
$$

The width of the diagonal strut $\omega$ was calculated using the relative stiffness parameter $\lambda h$ proposed by Smith (1962), where the two constants $\mathrm{K} 1$ and $\mathrm{K} 2$ were calibrated using results from experimental tests (Table 4):
Table 4 Coef. $K_{1}$ and $K_{2}$

\begin{tabular}{llc}
\hline & $K_{1}$ & $K_{2}$ \\
\hline$\lambda h \leq 3.14$ & 1.3 & -0.178 \\
$3.14 \leq \lambda h \leq 7.85$ & 0.707 & 0.01 \\
$\lambda h \leq 7.85$ & 0.47 & 0.04 \\
\hline
\end{tabular}

$\omega=\left(\frac{K_{1}}{\lambda h}+K_{2}\right) d$

$\lambda h=\sqrt[4]{\frac{E_{m} e \sin 2 \theta}{4 E_{c} I H}} h$

$d$ : equivalent strut length.

$E_{m}$ : infills' elastic equivalent modulus [4312 (MPa)].

$E_{c}$ : concrete elastic modulus;

$e$ : masonry panels' thickness;

$\theta$ : equivalent strut angle $(H \backslash L)$ (Fig. 5);

I: columns' moment of inertia;

$H$ : story height (Fig. 5);

$h$ : masonry panels' height (Fig. 5);

The Decanini et al.'s model backbone curve for the equivalent strut model is shown in Fig. 6.

The infill panel strength was simulated by a fictitious compressive failure stress $\sigma_{\mathrm{br}}$, computed as the lowest of the stresses corresponding to the four basic failure modes: diagonal tension $\left(\sigma_{\mathrm{br}_{1}}\right)$, sliding shear along the horizontal joints $\left(\sigma_{\mathrm{br}_{2}}\right)$, crushing in the corners in contact with the frame $\left(\sigma_{\mathrm{br}_{3}}\right)$ and diagonal compression $\left(\sigma_{\mathrm{br}_{4}}\right)$.

The ultimate lateral strength $H_{\mathrm{mfc}}$ is thus:

$$
\begin{aligned}
H_{\mathrm{mfc}} & =\sigma_{\min } e \omega \cos \theta \\
\sigma_{\min } & =\min \left\{\sigma_{\mathrm{br}_{1}}, \sigma_{\mathrm{br}_{2}}, \sigma_{\mathrm{br}_{3}}, \sigma_{\mathrm{br}_{4}}\right\} .
\end{aligned}
$$



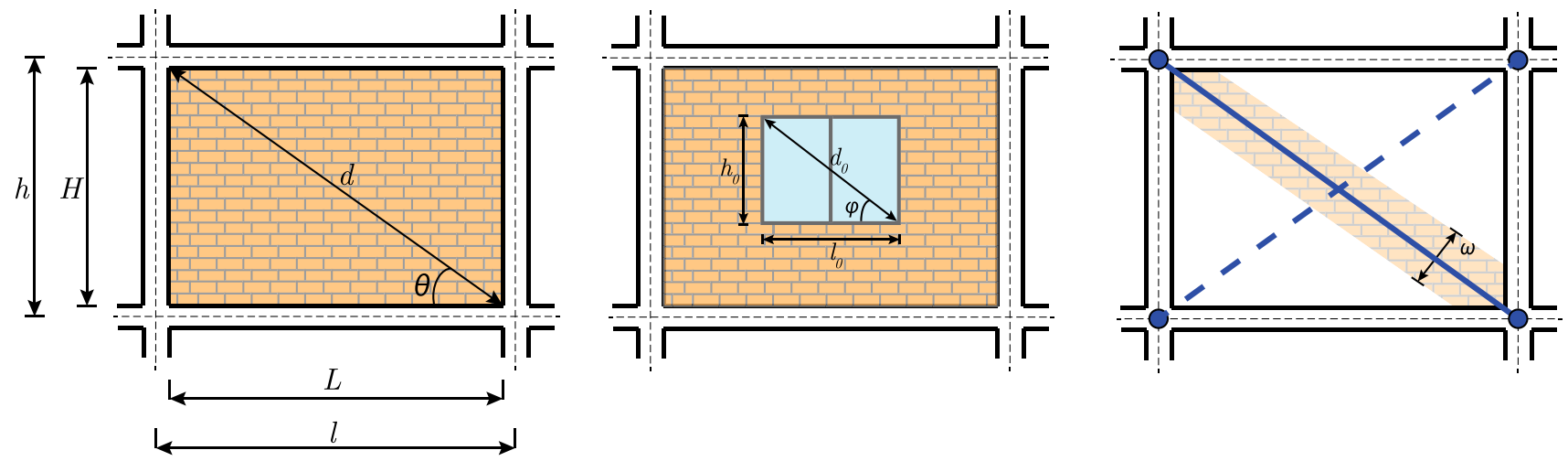

Fig. 5 Infill model by Decanini and Fantin (1987), Bertoldi et al. (1993), and Decanini et al. (2004): notation and main parameters of equivalent strut model

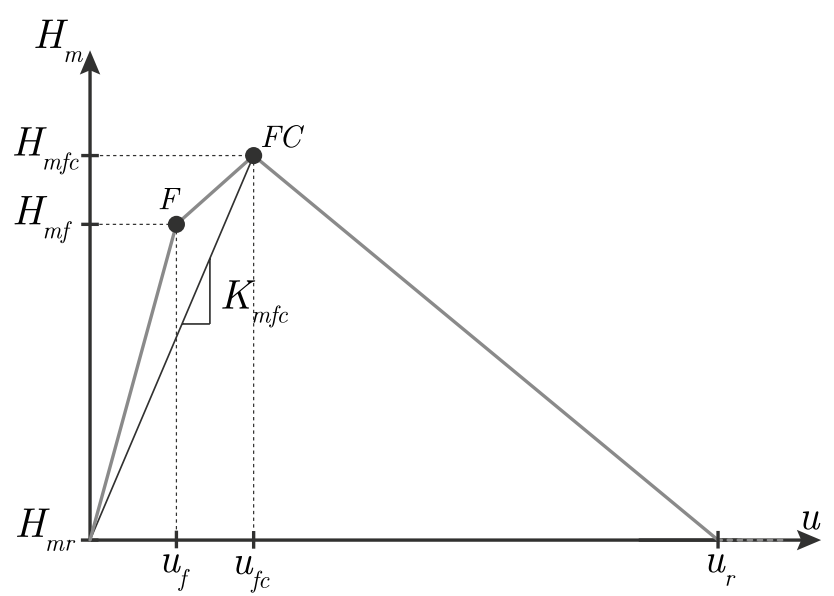

Fig. 6 Backbone curve for the equivalent strut model by Decanini and Fantin (1987), Bertoldi et al. (1993), and Decanini et al. (2004)

The ultimate lateral strength $H_{\mathrm{mfc}}$ was incremented by a factor estimated at 1.18 to obtain the median value, selected because the experimental database results on $H_{\mathrm{mfc}}$ were fitted with a log-normal distribution. The stiffness of the equivalent strut $K_{\mathrm{mfc}}$ was estimated using the following relation:

$K_{\mathrm{mfc}}=\frac{E_{m} e \omega}{d} \cos ^{2} \theta$.

The presence of openings in the infills was taken into account using reduction factors for the panels' stiffness and ultimate strength, according to the recommendations by Decanini et al. (2014)

$$
\begin{aligned}
& H_{\mathrm{mfc}, o}=H_{\mathrm{mfc}, o} \cdot \rho_{o} \\
& K_{\mathrm{mfc}, o}=K_{\mathrm{mfc}, o} \cdot \rho_{o} \\
& \rho_{o}=0.55 \exp \left(-0.035 \alpha_{a}\right)+0.44 \exp \left(-0.025 \alpha_{1}\right) \\
& \text { where } \alpha_{a}=\left(l_{0} h_{0} \backslash L H\right) 100 e \alpha_{1}=\left(l_{0} \backslash L\right) 100 .
\end{aligned}
$$

The original model by Decanini et al. (2014) was updated based on recent work Cardone and Perrone (2015) and Sassun et al. (2016), where the masonry infill drift limits are revisited based on an updated experimental database.

The infills were modeled in Opensees with the Concrete 01 material.

\section{Results of non-linear analyses}

Non-linear static and dynamic analyses were performed on the non-linear models. Figures 7 and 8 show the pushover curves for two different force distributions (Uniform and Modal) for the Naples and L'Aquila buildings, respectively.

In the $Y$ direction, there are two PO curves that refer to pushing in the positive and negative directions. The staircases make be building response different in the push and pull directions.

In the RINTC project, the EDP is the roof displacement and the capacity is determined as the displacement corresponding to the post-peak $50 \%$ decrease in base shear in the Pushover analyses. Different values are computed in the $X$ and $Y$ directions for the three structural configurations (BF, IF, PF). In each direction, the smallest displacement capacity governs. Table 5 reports the displacement capacities for the different cases, as determined from the PO analyses.

In the present work, the collapse EDPs of Table 1 are computed from "multi-stripe analyses" (MSA) (Jalayer 2003; Jalayer and Cornell 2009). The record selection was carried out in a parallel study Iervolino et al. (2017), where the selection algorithm is based on the Conditional Spectrum (CS) approach (Baker 2010; Jayaram et al. 2011; Lin et al. 2013) for ten intensity measure levels each representing a selection to a common spectral acceleration $S_{a}\left(T_{1}\right)$ defined for the return period of seismic action. Table 6 summarizes the $S_{a}(T)$ for the 10 IML together with the corresponding return periods. Since the ground motion records were selected based on spectrum compatibility at $S_{a}(T)$, with $T$ 

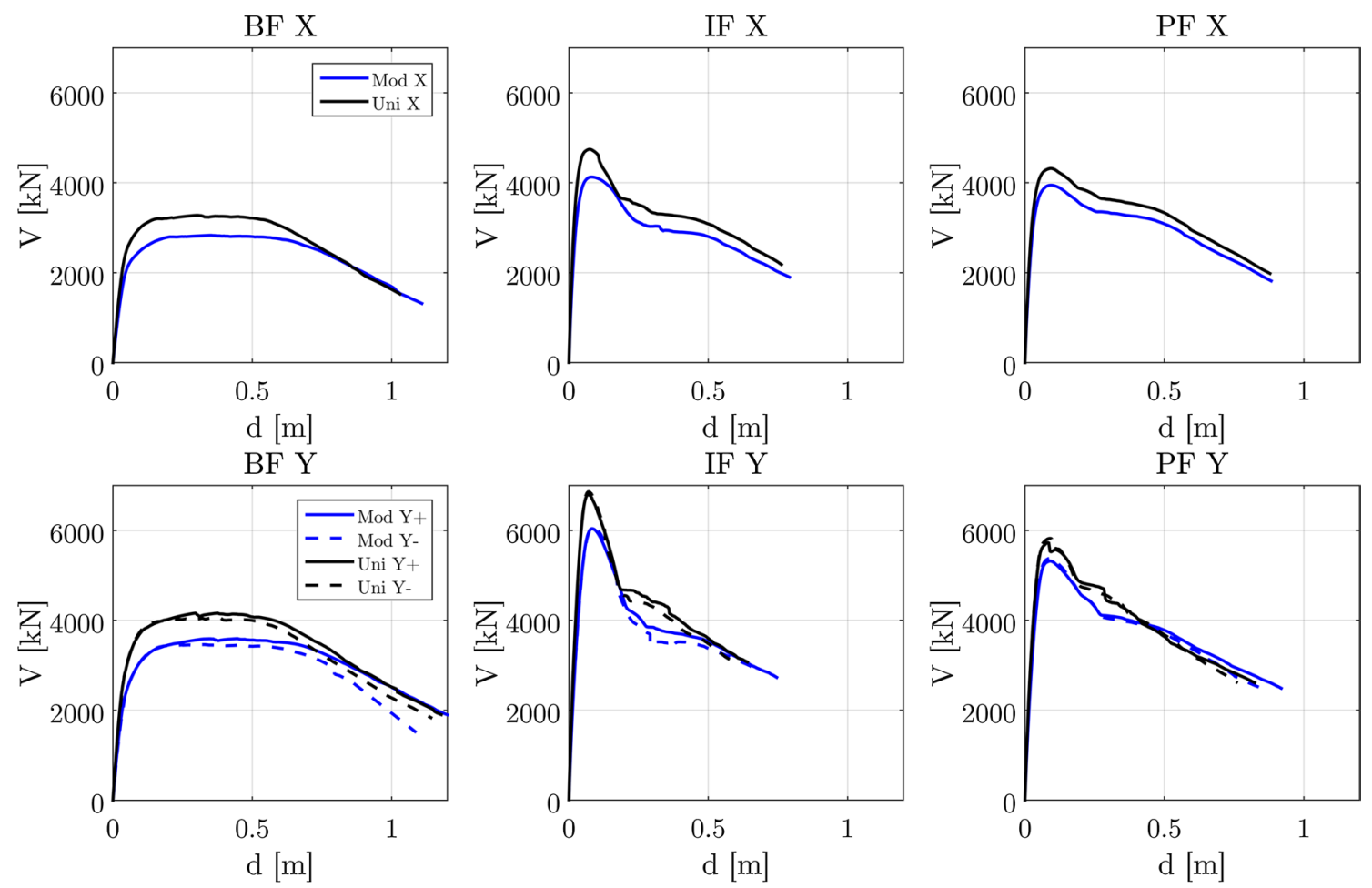

Fig. 7 Pushover responses for Naples-6s building
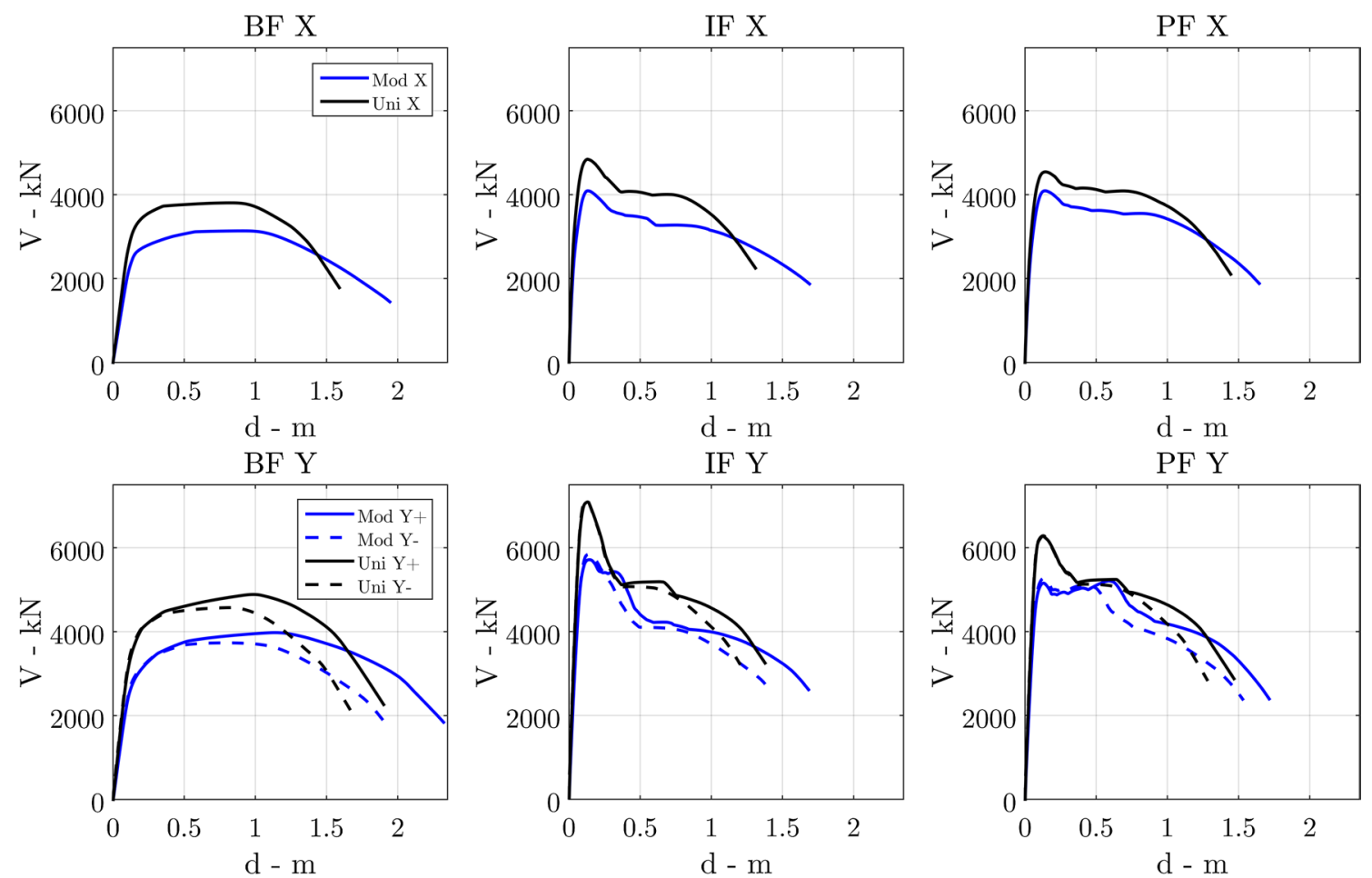

Fig. 8 Pushover responses for L'Aquila-9s building 
Table 5 RINTC capacity

\begin{tabular}{llllll}
\hline Typology & \multicolumn{2}{l}{ Napoli-6s } & & \multicolumn{2}{l}{ L'Aquila-9s } \\
\cline { 2 - 3 } \cline { 6 - 6 } & $X$ & $Y$ & & $X$ & $Y$ \\
\hline BF & 1.04 & 0.98 & 1.57 & 1.65 \\
IF & 0.86 & 0.71 & 1.28 & 1.14 \\
PF & 1.04 & 0.89 & & 1.42 & 1.24 \\
\hline
\end{tabular}

Table $6 S_{a}\left(T \approx T_{1}\right)$ for 10 IML Naples (NA) and L'Aquila (AQ)

\begin{tabular}{|c|c|c|c|c|c|}
\hline \multirow[t]{3}{*}{ IML } & \multirow[t]{3}{*}{$T_{R}$ (years) } & \multicolumn{4}{|c|}{$S_{a}\left(T \approx T_{1}\right)(\mathrm{g})$} \\
\hline & & NA IF-PF & NA BF & AQ IF-PF & AQ BF \\
\hline & & $\begin{array}{l}{[T=0.5} \\
(\mathrm{s})]\end{array}$ & $\begin{array}{l}{[T=1.5} \\
(\mathrm{s})]\end{array}$ & $\begin{array}{l}{[T=1.0} \\
(\mathrm{s})]\end{array}$ & {$[T=2.0(\mathrm{~s})]$} \\
\hline 1 & 10 & 0.043 & 0.010 & 0.029 & 0.011 \\
\hline 2 & 50 & 0.119 & 0.031 & 0.073 & 0.026 \\
\hline 3 & 100 & 0.226 & 0.061 & 0.139 & 0.049 \\
\hline 4 & 250 & 0.343 & 0.094 & 0.232 & 0.080 \\
\hline 5 & 500 & 0.480 & 0.134 & 0.365 & 0.124 \\
\hline 6 & 1000 & 0.637 & 0.180 & 0.558 & 0.184 \\
\hline 7 & 2500 & 0.834 & 0.235 & 0.855 & 0.270 \\
\hline 8 & 5000 & 1.051 & 0.292 & 1.217 & 0.379 \\
\hline 9 & 10000 & 1.393 & 0.383 & 1.837 & 0.572 \\
\hline 10 & 100000 & 2.114 & 0.573 & 3.520 & 1.077 \\
\hline
\end{tabular}
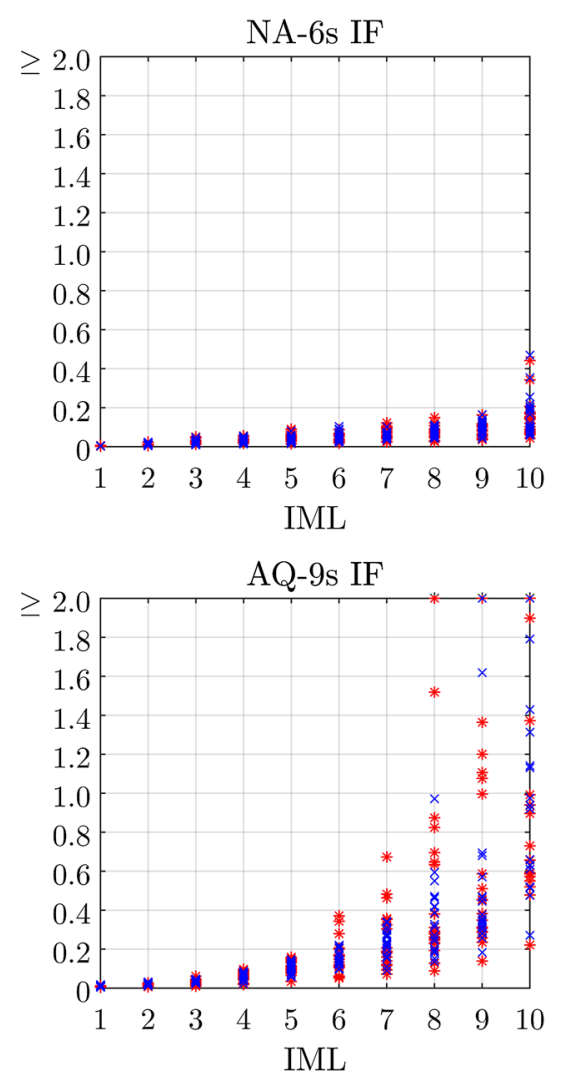
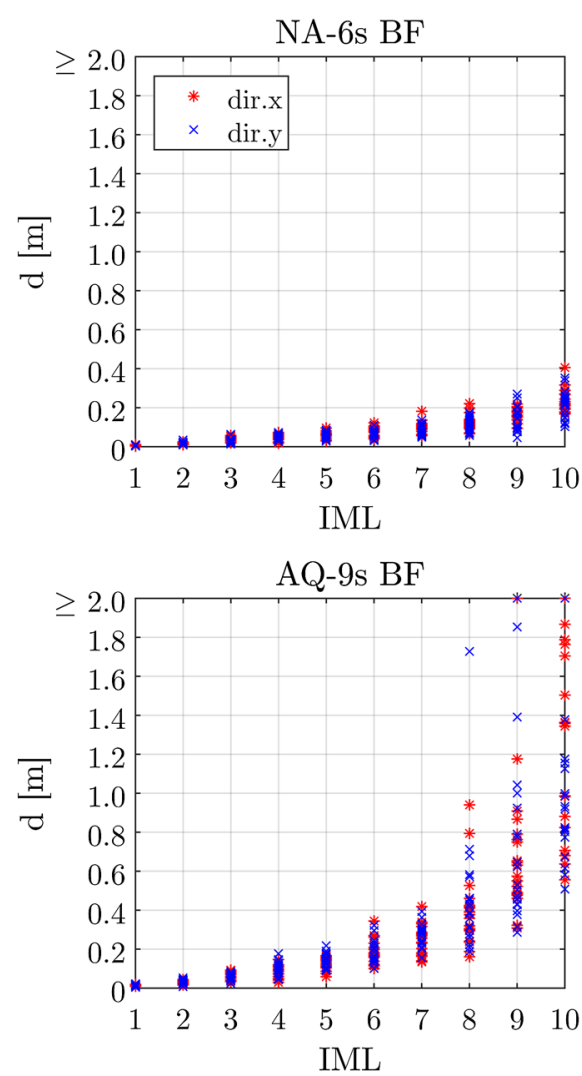

IML

IML equal to $0.25,0.5,1.0,1.5$, and $2.0 \mathrm{~s}$, given that the structure fundamental period $T_{1}, T$ was selected as the closest to $T_{1}$ of the above periods, thus the different periods in Table 6. Each stripe (or IML) is made of 20 pairs (two horizontal directions) of ground motion records.

The MSA results are reported by taking as representative parameters the maximum displacement in both directions of a control node at the roof (Fig. 9), and the maximum IDR (Fig. 10) of all floors in both directions. In cases, where non-linear dynamic analyses did not converge, the results of the last step to which convergence has been obtained are reported. Figures 9 and 10 show very high top displacement and IDR for the LAquila buildings. This is due to the high ductility of the structures that were designed following capacity design principles.

\section{Collapse rates for different EDPs}

For the previously defined EDPs, the D/C ratios are reported for the different non-linear time histories analyses at all ten intensity measure level (IML). Collapse is reached when $D / C \geq 1$. For the NTC2008 and EC8 EDP (cord rotation), the capacity is computed from the codes formulas. For the FEMA 356, Vision 2000 and Ghobarah (2004) EDP IDR,
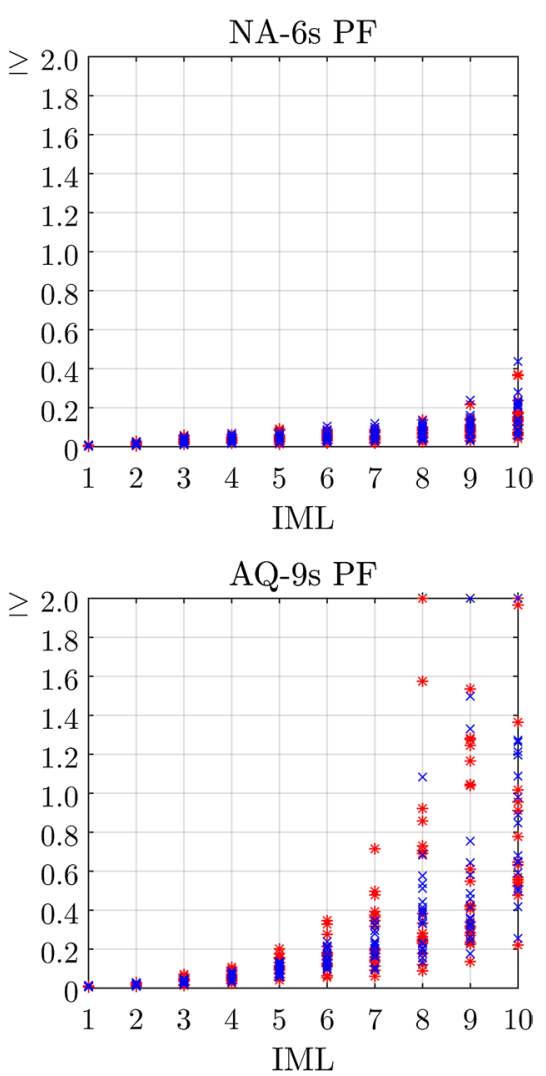

Fig. 9 Maximum roof control node displacement 

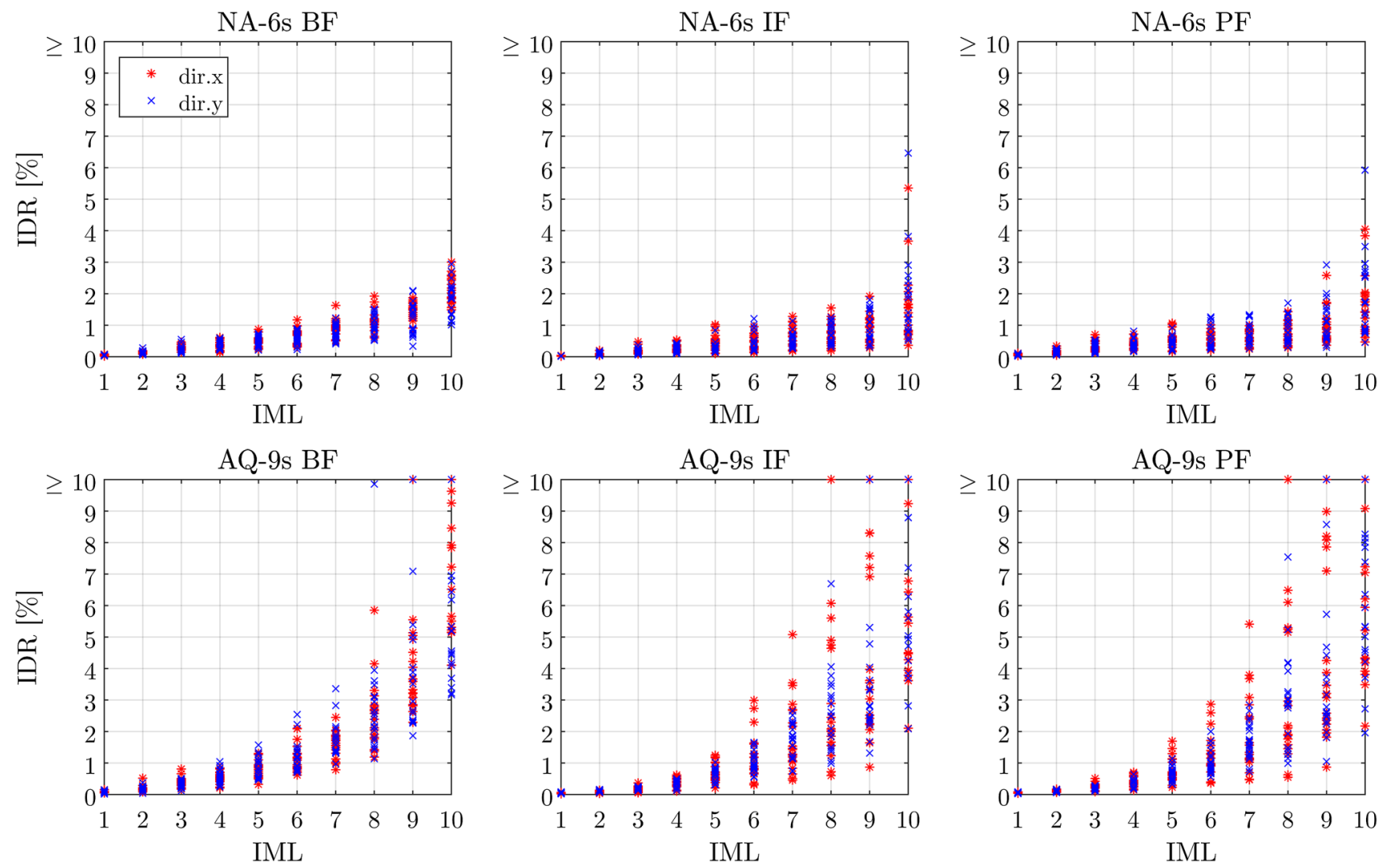

Fig. 10 Maximum IDRs

the capacity is computed from the definitions in the different documents. For the RINTC project EDP (top displacement or RDR), the capacity was computed from the PO analyses, as previously discussed (values are reported in Table 5). For all EDPs, the demand was obtained directly from the nonlinear dynamic analyses.

In the six-story building, the results in terms of $D / C$ (Figs. 11, 12,13) show that the RINTC criterion is the least conservative for defining the collapse of all the criteria
Fig. $11 D / C$ results for different EDPs for the Naples 6-story building-BF

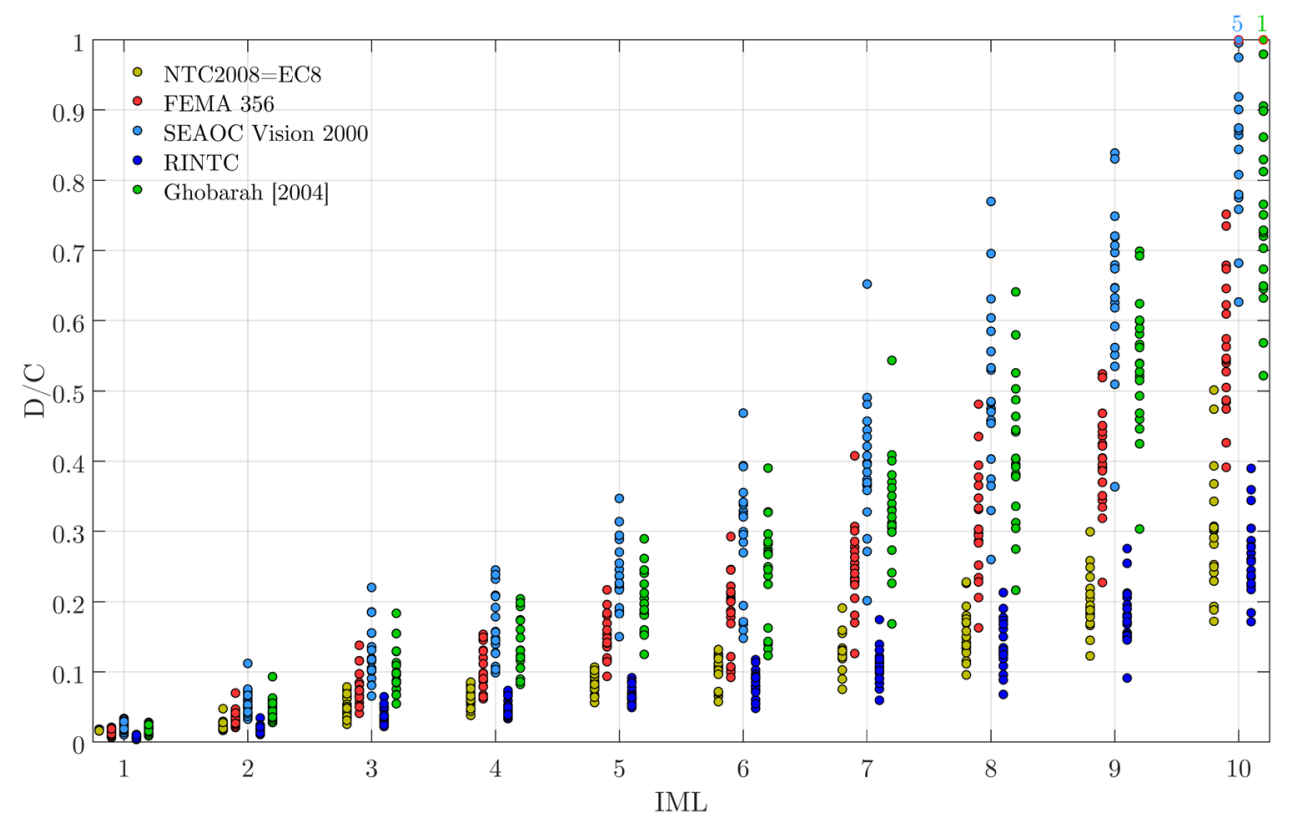


Fig. $12 D / C$ results for different EDPs for the Naples 6-story building-IF
Fig. $13 D / C$ results for different EDPs for the Naples 6-story building- $\mathrm{PF}$
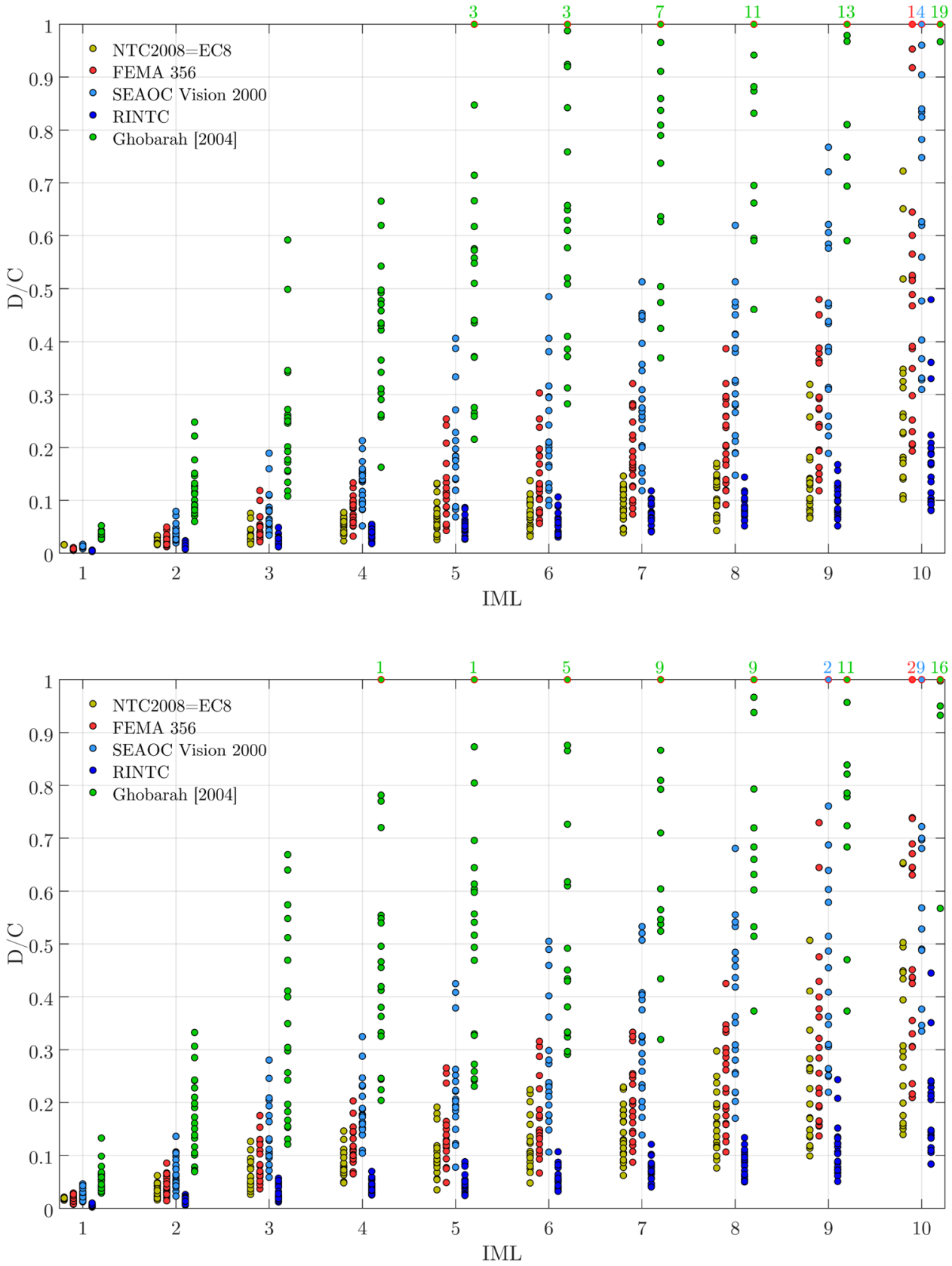

adopted for the three configurations (BF, IF, PF). In the case of $\mathrm{BF}$ typology, the next most conservative criterion is the IDR of SEAOC Vision2000, followed by the criterion of Ghobarah. Things are reversed in the infill typologies (IF, $\mathrm{PF})$, where Ghobarah turns out to be overly conservative, since the $D$ / $C$ value is much larger than in the other criteria. The FEMA356 EDP is the most conservative of the criteria based on the IDR (SEAOC Vision2000, Ghobarah). The results based on an element EDP collapse definition (NTC2008, EC8) tend to be in an intermediate condition between the RINTC EDP and the of FEMA356 criterion. In the L'Aquila nine-story building, the results in terms of $D / C$ (Figs. 14, 15, 16) show greater homogeneity for the different collapse criteria (FEMA 356, SEAOC Vision 2000, Ghobarah). The Ghobarah EDP appears to be overly conservative for the buildings with infills (IF, PF) for the less intense IM strips. The RINTC criterion is the least conservative. The element EDP (NTC2008, EC8) provides intermediate prediction among the IDR criteria (FEMA 356, SEAOC Vision 2000, Ghobarah). 
Fig. $14 D / C$ results for different EDPs for the L'Aquila 9-story building-BF
Fig. $15 D / C$ results for different EDPs for the L'Aquila 9-story building-IF
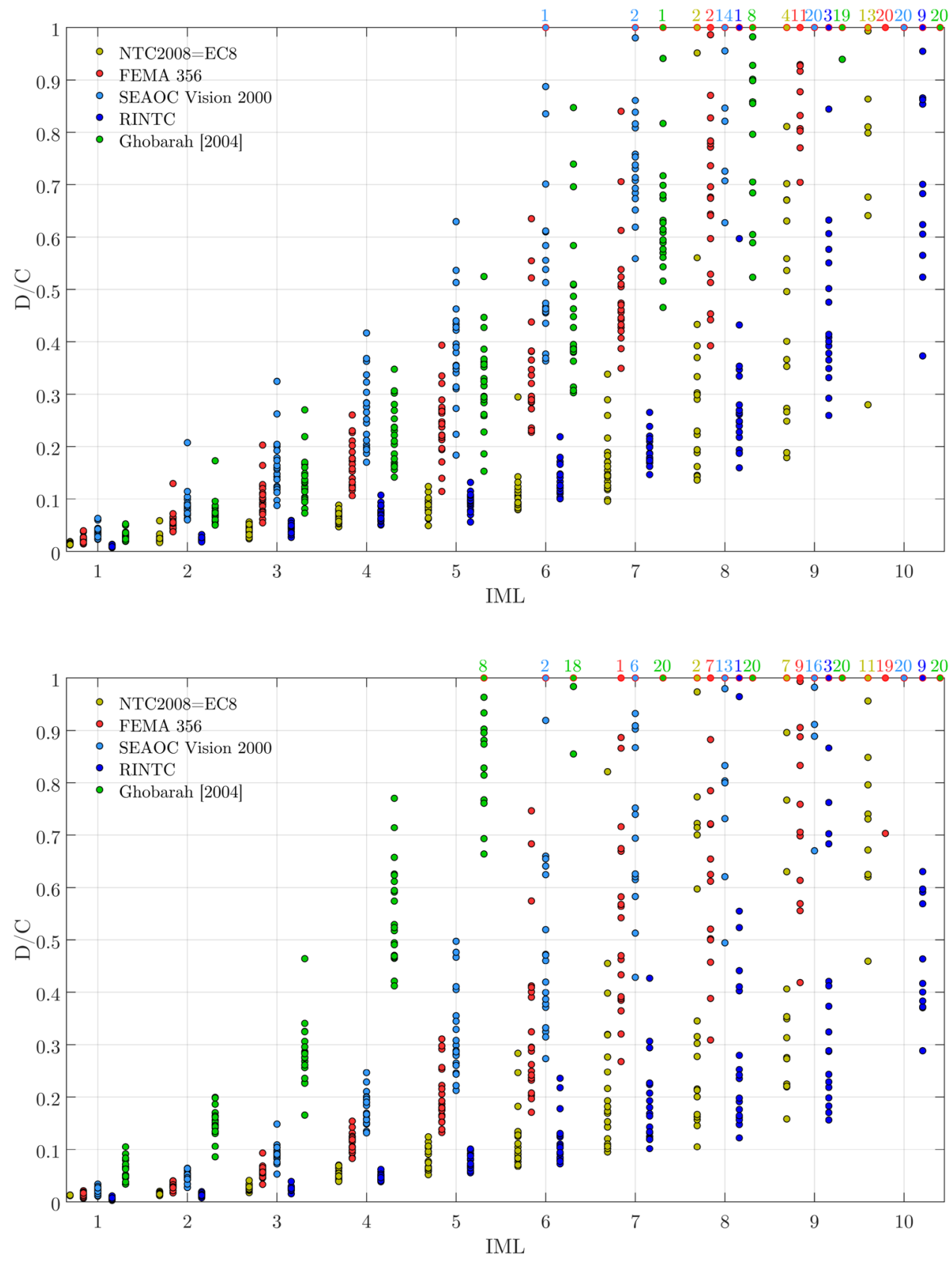

\section{Conclusions}

The different definitions of collapse available in building codes and the published literature lead to highly scattered collapse predictions, particularly for the six-story buildings in Naples. All criteria are, however, based on solid experimental results or sound engineering judgement. More specifically, the RINTC EDP is the most unconservative criterion. Only the Ghobarah EDP collapse value appears to be off for infill structures: its limit value is too high (IDR $=0.8 \%$ ) compared to the bare frame case (IDR $=3.0 \%$ ).
All EDPs considered in this work show limitations. The chord rotation used in Eurocode 8 and NTC 2008 is a local parameter. Strictly speaking, the first section that reaches the collapse chord rotation indicates global collapse. It is debatable whether beam collapse corresponds to global collapse. In the present study, only column collapse was considered. However, the chord rotation remains a local parameter whose link to global collapse is questionable. On the other hand, IDR and RDR are global parameters that consider the overall building behavior or compare story responses. The problem is that different documents propose different capacity values [for IDR, FEMA 356, Vision 2000 and Ghobarah 
Fig. $16 D / C$ results for different EDPs for the L'Aquila 9-story building- $\mathrm{PF}$

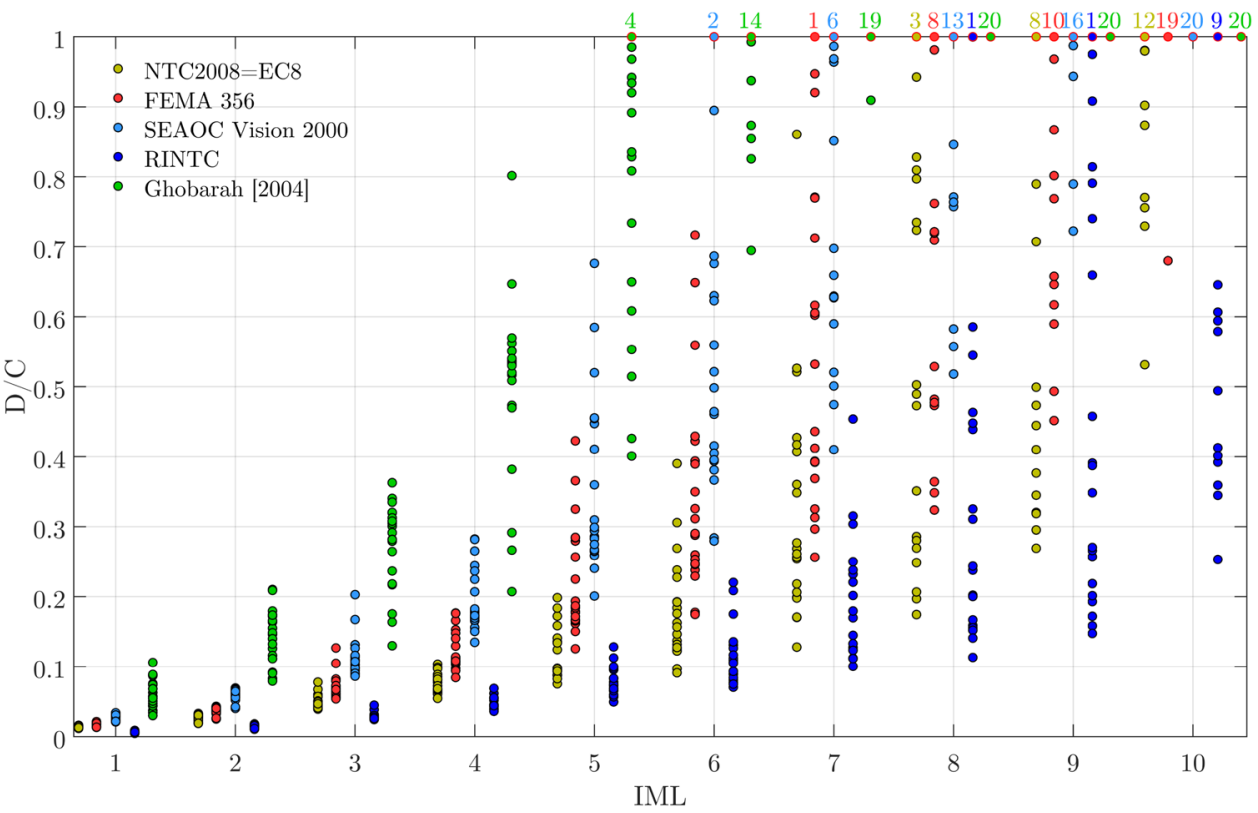

(2004), for RDR used in RINTC project, the capacity was defined here based on preliminary PO analyses].

Finally, it is not possible to establish which of these criteria is the most accurate one for the definition of collapse. All show that a properly designed building has a low collapse rate on average and in line with that for which it was designed. There appears to be the need to a unified definition of collapse, followed by a common EDP for measuring collapse and a common EDP collapse limit, to properly compare collapse rates in different countries.

Acknowledgements The authors acknowledge the great research efforts of the RINTC Workgroup of the 2015-2018 Reluis project, whose work inspired the research topic presented in this paper. Partial support by the ReLUIS (Italian Network of Earthquake Engineering University Laboratories) project funded by the Italian Department for Civil Protection is acknowledged (http://www.reluis.it).

Open Access This article is distributed under the terms of the Creative Commons Attribution 4.0 International License (http://creativeco mmons.org/licenses/by/4.0/), which permits unrestricted use, distribution, and reproduction in any medium, provided you give appropriate credit to the original author(s) and the source, provide a link to the Creative Commons license, and indicate if changes were made.

\section{References}

Baker JW (2010) Conditional mean spectrum: tool for ground-motion selection. J Struct Eng 137(3):322-331

Bertoldi SH, Decanini L, Gavarini C (1993) Telai tamponati soggetti ad azioni sismiche, un modello semplificato: confronto sperimentale e numerico, vol 6. In: Atti del VI convegno nazionale ANIDIS, Perugia, pp 815-824

Camata G, Celano F, De Risi MT, Franchin P, Magliulo G, Manfredi V, Masi A, Mollaioli F, Noto F, Ricci P, Spacone E, Terrenzi M,
Verderame G (2017) RINTC project: nonlinear dynamic analyses of Italian code-conforming reinforced concrete buildings for risk of collapse assessment. In: COMPDYN 2017-6th ECCOMAS thematic conference on computational methods in structural dynamics and earthquake engineering, Rhodes Island, pp 15-17

Cardone D, Perrone G (2015) Developing fragility curves and loss functions for masonry infill walls. Earthq Struct 9(1):257-279

Decanini L, Fantin G (1987) Modelos simplificados de la mampostería incluida en porticos. Caracteristicas de stiffnessy resistencia lateral en estado limite, vol 2. Jornadas Argentinas de Ingeniería Estructural, pp 817-836

Decanini L, Mollaioli F, Mura A, Saragoni R et al (2004) Seismic performance of masonry infilled R/C frames, vol 165. In: 13th world conference on earthquake engineering

Decanini LD, Liberatore L, Mollaioli F (2014) Strength and stiffness reduction factors for infilled frames with openings. Earthq Eng Eng Vib 13(3):437-454

Ghobarah A (2004) On drift limits associated with different damage levels. Performance-based seismic design concepts and implementation, vol 28. Proceedings of the international workshop, Bled, pp 321-332

Haselton CB, Liel AB, Deierlein GG (2009) Simulating structural collapse due to earthquakes: model idealization, model calibration, and numerical solution algorithms. In: Computational methods in structural dynamics and earthquake engineering (COMPDYN)

Ibarra LF, Medina RA, Krawinkler H (2005) Hysteretic models that incorporate strength and stiffness deterioration. Earthq Eng Struct Dyn 34(12):1489-1511

Iervolino I, Spillatura A, Bazzurro P (2017) RINTC project-assessing the (implicit) seismic risk of code-conforming structures in Italy. In: COMPDYN 2017-6th ECCOMAS thematic conference on computational methods in structural dynamics and earthquake engineering, Rhodes Island, pp 15-17

Jalayer F (2003) Direct probabilistic seismic analysis: implementing non-linear dynamic assessments. Ph.D. thesis, Stanford University, Stanford

Jalayer F, Cornell C (2009) Alternative non-linear demand estimation methods for probability-based seismic assessments. Earthq Eng Struct Dyn 38(8):951-972 
Jayaram N, Lin T, Baker JW (2011) A computationally efficient ground-motion selection algorithm for matching a target response spectrum mean and variance. Earthq Spectra 27(3):797-815

Lignos DG, Krawinkler H (2012) Development and utilization of structural component databases for performance-based earthquake engineering. J Struct Eng 139(8):1382-1394

Lin T, Haselton CB, Baker JW (2013) Conditional spectrum-based ground motion selection. Part I: Hazard consistency for risk-based assessments. Earthq Eng Struct Dyn 42(12):1847-1865

McKenna F (2011) Opensees: a framework for earthquake engineering simulation. Comput Sci Eng 13(4):58-66

Panagiotakos TB, Fardis MN (2001) Deformations of reinforced concrete members at yielding and ultimate. Struct J 98(2):135-148

RINTC Workgroup (2018) Results of the 2015-2017 RINTC project, ReL UIS report. Tech. report. ReL UIS, Naples

Sassun K, Sullivan TJ, Morandi P, Cardone D (2016) Characterising the in-plane seismic performance of infill masonry. Bull N Z Soc Earthq Eng 49(1):100-117
Smith BS (1962) Lateral stiffness of infilled frames. J Struct Div 88(6): 183-226

Villaverde R (2007) Methods to assess the seismic collapse capacity of building structures: state of the art. J Struct Eng 133(1):57-66

Whittaker A, Deierlein G, Hooper J, Merovich A (2004) Engineering demand parameters for structural framing systems. ATC 58 Structural Performance Products Team, Redwood

Publisher's note Springer Nature remains neutral with regard to jurisdictional claims in published maps and institutional affiliations. 